\title{
O ESTADO DE RECREIO DA CRIANÇA NO PROCESSO DE DRAMA
}

\author{
EL ESTADO DE RECREO DEL NIÑO EN EL PROCESO DE DRAMA
}

\author{
A CHILD'S BREAK-TIME MOOD IN THE DRAMA PROCESS
}

\author{
Diego de Medeiros Pereira \\ Maria Jade Pohl Sanches
}

\begin{abstract}
RESUMO
Este texto aborda reflexões sobre uma prática de Drama desenvolvida com uma turma do quarto ano em uma escola pública do município de Santa Maria (RS). Na análise do processo, propôs-se a seguinte questão: o estado de jogo que a criança apresenta no Drama é o mesmo que ela experimenta no recreio escolar? O "estado de recreio" defendido por Souza (2014) parece se aproximar da "imersão" proposta por Cabral (2006) e Pereira (2015), ao tratarem da atitude experimentada pelos participantes em um processo de Drama. Evidencia-se o potencial do Drama para tratar de temas contemporâneos, aliado a um processo de aprendizagem do teatro que se dá de forma lúdica e participativa.
\end{abstract}

PALAVRAS-CHAVE: teatro e infâncias, teatro na escola, processo de Drama

\section{RESUMEN}

Este texto enfoca reflexiones acerca de una práctica de Drama desarrollada con una clase del cuarto año en una escuela pública de la ciudad de Santa Maria (RS). En el análisis del proceso, se propuso la siguiente cuestión: ¿el estado de juego que el niño presenta en el Drama es el mismo que él experimenta en el recreo escolar? El "estado de recreo" defendido por Souza (2014) parece acercarse a la "inmersión" propuesta por Cabral (2006) y Pereira (2015), al tratar de la actitud experimentada por los participantes en un proceso de Drama. Se evidencia el potencial del Drama para tratar de temas contemporáneos, aliado a un proceso de aprendizaje del teatro que se da de forma lúdica y participativa.

Palabras clave: teatro y infancias, teatro en la escuela, proceso de Drama.

\begin{abstract}
This text brings forth considerations about the practice of Drama. This practice has been carried out in a public school in the city of Santa Maria (RS) with a fourth grade class. In the analysis of the process, the following question has been proposed: is the playful mood that a child experiences in a Drama practice the same it experiences during the break-time at school? This "break-time mood" defended by Souza (2014) seems to come close to the idea of "immersion" proposed by Cabral (2006) and Pereira (2015) when they deal with the attitude experienced by the participants in a processo of Drama. It has become clear that the use of Drama techniques can lead to a critical reflection on contemporary issues, wich happens in a playful, participative way.
\end{abstract}

Keywords: theater and the childhood, theather in the school, process Drama 


\section{Introdução}

O presente artigo parte do seguinte questionamento: o estado de jogo que a criança apresenta no Drama é semelhante ao que ela experimenta no recreio escolar? O objetivo desta reflexão é discutir a proximidade entre o estado que as crianças experimentam na situação ficcional que o Drama propõe, com o modo que elas agem no recreio. Como material de análise, exporemos um processo de Drama desenvolvido com crianças do $4^{\circ}$ ano do Ensino Fundamental da EMEF Pe. Gabriel Bolzan, localizada na cidade de Santa Maria (RS) por meio de um projeto contemplado pelo Edital do Programa das Licenciaturas (PROLICEN/UFSM/2017).

O Drama é uma abordagem inglesa para o ensino e experimentação teatrais que tem se difundido no Brasil nos últimos anos, sobretudo por meio dos trabalhos realizados por Beatriz Cabral. Vemos como importante a exploração do Drama nessa prática teatral proposta na escola, por se tratar de uma abordagem que promove a imersão das crianças em contextos ficcionais, ampliando sua capacidade de jogo, sua expressividade corporal, suas potencialidades criativas, sem o foco na elaboração de um produto artístico.

Para fundamentar os escritos ora apresentados e como modo de subsidiar as reflexões advindas da prática, utilizaremos das referências adotadas no desenvolvimento do Projeto: Cabral (2006), Vidor (2010) e Pereira (2015), os quais abordam diferentes convenções e estratégias para a proposição e desenvolvimento de processos de Drama.

Em um segundo momento, discorreremos sobre o processo "No reino de Saint Mary", Drama inspirado no texto "Romeu e Julieta", de William Shakespeare. Ao longo da exposição, refletiremos sobre as estratégias utilizadas e suas reverberações nas ações propostas pelas crianças.

Por fim, apresentaremos o conceito de "Estado de Recreio", proposto por Souza (2014), com o qual estabeleceremos paralelos, uma vez que, parece-nos que esse estado, assumido pela criança no intervalo das aulas, assemelha-se àquele por ela experimentado quando imersa na situação ficcional proposta pelo Drama.

Somos levados a compreender que o modo de ensino-aprendizagem do teatro proporcionado pelo Drama, propõe a elaboração de uma experiência diferenciada que 
foge de um padrão pré-estabelecido de fazer teatro. Esse diferencial é defendido como a instauração de um estado em que o educando aprende e cria de modo lúdico, divertido e participativo.

\section{Apresentando o Drama}

O Drama, segundo Beatriz Cabral (2006, p.10), "é uma atividade criativa em grupo, na qual os participantes se comportam como se estivessem em outra situação ou lugar sendo eles próprios ou outras pessoas". Essa atividade lúdica é a base para o trabalho com uma abordagem de ensino-aprendizagem do teatro denominada Processo de Drama ou, apenas, Drama. Um processo de Drama é dividido em diversos episódios, os quais existem como unidades cênicas que permitem a criação de uma sequência nas atividades propostas dentro de um determinado contexto ficcional, possibilitando a imersão das crianças na narrativa criada a partir da parceria criança-professor-criança.

Cabral (2006) expõe as principais convenções para a instauração de um processo de Drama. Para que se inicie um processo de Drama é necessário um pré-texto, ou seja, um material de apoio (uma narrativa, um texto dramático, conto, reportagens, roteiro, entre outras possibilidades) que será utilizado como pano de fundo para as criações que surgirão. Segundo O’Neill (1995, p. 22), “[...] o pré-texto opera em diferentes momentos como uma espécie de 'forma-suporte' para os demais significados a serem explorados". Nesse sentido, o condutor de um processo possui uma referência a qual ele pode recorrer caso faltem ideias de como prosseguir com a narrativa ou quais outras situações propor aos participantes.

O papel do professor, nessa abordagem, é provocar questionamentos e desafios, mobilizando os estudantes à ação, a fim de que resolvam os conflitos da trama e prossigam contribuindo com a construção da história. Em geral, o professor assume personagens ou papéis durante o processo, concentrando as ações e discussões dentro do contexto ficcional criado e se colocando, também, como artista, ao criar personagens e maneiras de agir e reagir às ações propostas pelas crianças. Segundo Vidor:

A escolha dos papéis a serem representados no processo de drama, coloca o professor inicialmente no papel de dramaturgo. Antes de pensar em como representará este papel e em sua potencialidade relacionada a exploração dos signos teatrais, o professor precisa alinhar-se com a característica essencial desta metodologia que envolve a construção de uma narrativa, 
portanto é importante que os papéis escolhidos tenham o poder de auxiliar a condução da narrativa tanto pelo professor quanto pelos alunos, de modo a ajudar com que os últimos se envolvam na ficção proposta. (VIDOR, 2010, p. 41).

Para as crianças, assim como para todos os participantes - afirmamos isso a partir de nossas experiências como condutores de processos - o Drama tem se mostrado uma experiência enriquecedora. Como afirma Murray:

A experiência de ser transportado a um local simulado, com tamanha precisão, é prazerosa em si, independente do conteúdo de sua fantasia. A esta experiência chamamos 'imersão', uma metáfora derivada da experiência física de submergir na água e ficar envolvido por uma realidade completamente diferente. (MURRAY apud CABRAL, 2006, p. 27).

O que temos percebido, e será apresentado a seguir a partir de uma experiência concreta, é justamente esse estado de imersão das crianças na narrativa proposta, não uma imersão que abandona completamente a relação das crianças com a realidade, mas uma forma de experimentarem, de modo lúdico e ficcional, situações do seu cotidiano e informações que possuem sobre o mundo. Imersas no contexto ficcional proposto, as crianças criam narrativas e experimentam o fazer teatral de uma maneira diferenciada, percebendo-se como criadoras e não apenas reprodutoras de uma história.

Ao verificarmos que em um processo de Drama as crianças se colocam como artistas, podemos vislumbrar uma abordagem que abre espaço para que elas sejam produtoras de cultura, sujeitos sociais ativos no processo de construção de conhecimentos e para que descubram diferentes modos de se expressarem no mundo. Nesse sentido, Prado aponta que:

[...] a cultura infantil, aquela que se expressa por pensamentos e sentimentos que chegam até nós, não só verbalmente, mas por meio de imagens e impressões que emergem do conjunto da dinâmica social, reconhecida nos espaços das brincadeiras e permeada pela cultura do adulto, não se constituía somente em obras materiais, mas na capacidade das crianças de transformar a natureza e, no interior das relações sociais, de estabelecer múltiplas relações com seus pares, com crianças de outras idades e com os adultos, criando e inventando novas brincadeiras e novos significados (PRADO, 2009, p. 101). 
O espaço da brincadeira é facilmente acessado pelas crianças durante o período da infância - isso quando há tempo/espaço para que brinquem¹, acesso esse que é reduzido na medida em que a criança cresce. $\mathrm{Na}$ escola, em geral, as brincadeiras são restritas aos momentos de recreio ou mesmo a algumas disciplinas que promovem algum tipo de jogo ou movimento - em geral, a Educação Física. Sabemos que o ensino do Teatro ainda é bastante incipiente no Brasil e que, portanto, poucas crianças possuem experiências com a linguagem teatral na aula de Artes, em geral restrita à exploração das Artes Visuais. Quando possuem, via de regra, resumem-se às enfadonhas montagens teatrais - com memorização de falas, marcações, brigas por papéis de destaque, vergonha de se apresentar, entre outras situações comuns a práticas tradicionais com essa linguagem.

Na instauração de um processo de Drama, buscamos ampliar e resgatar o espaço de jogo, típico das brincadeiras infantis, incentivando as crianças a "comprarem" a proposta, experimentando papéis dentro de um determinado "faz de conta" (contexto ficcional) e aprendendo sobre Teatro de uma maneira diferenciada.

Com o intuito de investigar as possibilidades artístico-pedagógicas do Drama e explorar seu potencial como abordagem para o ensino e experimentação do Teatro, desenvolvemos, no ano de 2017, o projeto "Drama e Infâncias: práticas pedagógicoteatrais com crianças" na Escola Municipal de Ensino Fundamental Pe. Gabriel Bolzan, na cidade de Santa Maria (RS). A prática instaurada, em diálogo com algumas reflexões geradas ao longo do processo, será retratada a seguir.

\section{O Projeto}

Com o apoio do Programa de Licenciaturas (PROLICEN) que tem por objetivo propiciar uma efetiva articulação dos cursos de Licenciatura com os ensinos Fundamental e Médio, propusemos a realização de 02 processos de Drama na EMEF Pe. Gabriel Bolzan, uma instituição pública de ensino, localizada no bairro Camobi, próxima à universidade. $\mathrm{O}$ primeiro processo foi instaurado com crianças do $4^{\circ}$ ano (com idades

\footnotetext{
${ }^{1}$ Não ignoramos o fato de que no Brasil muitas crianças são impossibilitadas de brincar porque vivem em situações sociais que exigem que exerçam, prematuramente, tarefas como cuidar de casa, de seus irmãos ou mesmo ajudar seus pais no sustento familiar, trabalhando.
} 
entre 09 e 10 anos) e o segundo, com crianças da Educação Infantil (com cerca de 05 anos de idade). Cabe ressaltar que o projeto foi articulado ao Grupo de Estudos sobre Teatro e Infâncias (GETIs/CNPq) o qual tem investigado práticas pedagógico-teatrais com e para crianças.

Para este texto, decidimos abordar o primeiro processo intitulado "O Reino de Saint Mary”, que contou com a participação de 17 crianças, além da presença efetiva da professora regente da turma. Primeiramente, foi realizada uma sondagem; levantamos o perfil do grupo e do espaço educacional onde realizaríamos o projeto com o intuito de buscar uma aproximação com o contexto real daqueles que seriam os participantes da proposta. Como aponta Pereira,

Para que a proposição de um Drama gere um engajamento dos participantes e auxilie na construção de conhecimentos significativos sobre o tema selecionado para se trabalhar, é importante observar o contexto do grupo [...]. O Drama não está interessado em representar uma história ou reproduzir estereótipos sobre determinado tema ou situação, ao contrário, ele busca a imersão dos participantes na experimentação dramática de uma situação que dialogue com a realidade e amplie a percepção das questões contidas no real (PEREIRA, 2015a, p. 121).

Após dois dias de observação da turma, realizadas pela bolsista do projeto, propusemos que as crianças respondessem a um questionário. Dentre as questões estavam: nome, cor favorita, filme preferido, jogo que mais gosta, um livro, se pudesse vivenciar um personagem qual seria e uma música. Essas respostas nos auxiliaram na escolha do pré-texto para o processo de Drama. Para nossa surpresa, o livro mais apontado pelo grupo foi "Romeu e Julieta", de William Shakespeare, que fora trabalhado pela professora regente durante o mês de junho, quando no Brasil comemoramos o dia dos namorados.

Escolhido o pré-texto, separamo-lo em 07 episódios, que seriam realizados uma vez por semana. Transformamos a sala de aula no Reino fictício de Saint Mary, do qual a bolsista, como professora-personagem, seria a princesa Jade e a professora regente ${ }^{2}$, sua Ama. Os estudantes (divididos em dois grupos) se tornariam membros de dois clãs - os vermelhos e os roxos (cores que mais apareceram como favoritas nos questionários) e a narrativa se passaria no ano de $1682^{3}$. Estava criado o contexto ficcional e definidos

\footnotetext{
2 Professora Vera Godói.

${ }^{3}$ Foi escolhido o ano de 1682 por se passar na Idade Moderna, época do Absolutismo, uma organização política na qual o soberano concentrava todos os poderes do estado em suas mãos.
} 
os primeiros papéis que, tanto professoras, quanto estudantes, desempenhariam na construção da narrativa.

Para Bowell e Heap: “[...] a atividade fundamental em qualquer tipo de Drama é assumir um papel - isto é, imaginar que você é uma outra pessoa em um contexto ficcional e explorar uma situação através dos olhos dessa pessoa” (2013, p. 33) e no momento em que tanto as professoras como os educandos assumem esses papéis, incumbem-se de desenvolverem um processo colaborativo de criação que resulta em uma dissolução, ainda que momentânea, das hierarquias tão firmemente sustentadas pela instituição Escola.

No primeiro episódio, denominado de “A criação dos Clãs”, foi proposto que cada grupo criasse sua bandeira, nome do clã e uma maneira de se apresentar para o outro grupo e para a princesa Jade. As crianças se mostraram curiosas com a proposta e ansiosas pela criação; não conseguindo terminar as bandeiras e apresentações, pediram para que retomássemos no próximo episódio. Nesse dia, percebemos a dificuldade do trabalho em equipe e uma certa resistência ao formar os clãs, sendo que alguns pediram para entrar em outro grupo; lidar com os pontos de vistas diferentes e tomarem decisões em conjunto, seria um desafio para os estudantes.

O segundo episódio teve o nome de "Os Cidadãos". Após a apresentação dos clãs, definidos pelas crianças como "Sanserine” (roxos) e "Guerreiros de Sangue" (vermelhos), solicitamos que cada criança criasse um cidadão para o reino, seu nome, profissão, idade, habilidades e segredos. Surgiram nomes e profissões interessantes e as crianças não fugiram da época que fora definida, escolheram profissões como o cocheiro, a cozinheira, o alfaiate, o guarda do castelo, a médica, a costureira, o guerreiro, o ferreiro, entre outros. Nesse episódio, refletimos sobre a disponibilidade das crianças em relação aos personagens criados, o entusiasmo por poderem realizar outros papéis e imaginar suas ações, o que lembrou as palavras de Cabral:

O contexto da ficção atua na capacidade do participante desempenhar papéis, projetando-se imaginária e fisicamente na situação; permite organizar momentaneamente a experiência em uma série de memórias e vivenciar situações não cotidianas através da história de outros. (CABRAL, 2011, p. 114).

O Terceiro Episódio foi "O Baile de Máscaras”, pensado como Festa de aniversário da Princesa Jade, mas antes, os cidadãos aprenderam uma dança de corte, 
que foi ensinada pelo personagem convidado como "O Duque coreógrafo". A festa foi interrompida pela descoberta de silhuetas de dois corpos (confeccionadas em papel craft) que foram colocadas no chão, indicando que duas pessoas (uma do clã Sanserine e outra dos Guerreiros de Sangue) foram assassinadas durante o baile e que os estudantes (cidadãos dos clãs) deveriam desvendar o crime cometido. Percebemos que as crianças estavam muito envolvidas com o processo; levaram presentes para a princesa que elas mesmas confeccionaram a partir de suas profissões na trama, criaram suas roupas e suas máscaras de baile com o auxílio da professora regente, que nos auxiliou como personagem em todos os momentos do processo. Notamos, também, a maturidade das crianças ao questionarmos sobre o motivo do assassinato: seria por amor? Por ciúmes? Mas seria "normal” matar por amor ou ciúmes? Reafirmamos a importância de permitir que as crianças encontrem as respostas através dos materiais, como aponta Pereira:

Ao coletar e analisar as respostas do grupo o professor fornecerá outros materiais que darão encaminhamento ao processo. Incentivará à reflexão dos participantes avaliando com eles os acontecimentos. Buscará quebrar com julgamentos de valor de certo ou errado, construindo conhecimentos sobre os significados das suas ações e reações. (PEREIRA, 2015a, p. 183).

Seguindo esses preceitos apontados por Pereira, organizamos o quarto episódio intitulado "As investigadoras". Com o uso das estratégias "estímulo composto" e "professor no papel" a professora regente e a bolsista assumiram os papéis de detetives. Inicialmente, lemos uma ordem enviada pelo Rei de Saint Mary, que impedia os cidadãos dos dois clãs de se comunicarem até que os assassinatos fossem desvendados, para isso, construímos um muro dentro da sala que dividia os dois grupos. Levamos, também, duas caixas, contendo conchas, folhas secas, chás, uma carta, um bilhete, uma aliança, um lenço branco, a imagem de um homem, a de uma mulher, um mapa e desenho de um castelo. Os estudantes deveriam indicar um(a) possível criminoso(a), assim como definir quem era o(a) morto(a) cuja caixa estava com eles e qual seria sua história. As crianças se envolveram muito com o episódio, criaram histórias sobre o assassinato e ficaram curiosas com a punição do assassino. Esse envolvimento se deu, em grande medida, pelo uso do "estímulo composto" ou "pacote de estímulos". Segundo John Somers:

A energia e o interesse gerados pelo estímulo composto são cruciais para assegurar o envolvimento do participante. $\mathrm{O}$ estímulo composto provê um forte reforço inicial para a criação 
da narrativa em cena e, uma vez que esta tenha sido iniciada, passa a servir como uma referência contínua no processo de criação. (SOMERS apud CABRAL, 2011, p.175).

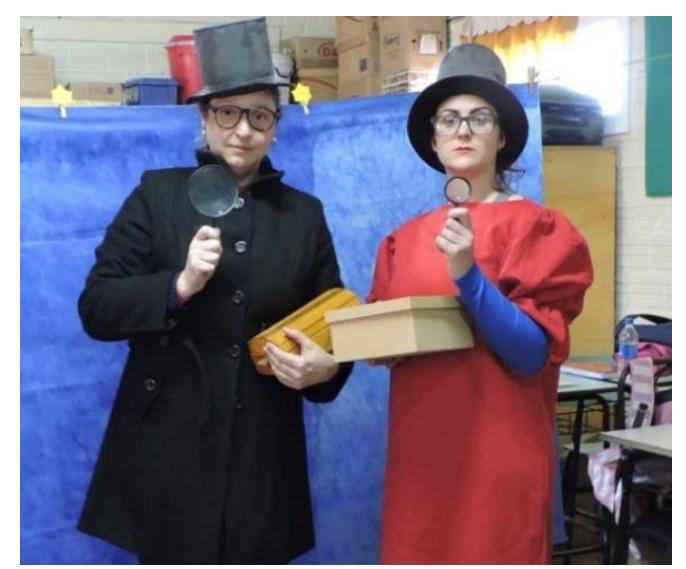

As investigadoras do Reino ${ }^{4}$

O quinto episódio foi chamado de "O Julgamento". Nesse episódio foram à escola personagens convidados para fazerem o papel de casais "banidos" do reino de Saint Mary por infringirem a lei do rei (cada casal era composto por um "membro" de cada clã, caracterizado por vestimentas em cores vermelhas ou roxas). Eram três casais, um com dois homens, outro com duas mulheres e o terceiro com um homem e uma mulher ${ }^{5}$. Os casais dançaram, em uma área aberta da escola, uma coreografia que sugeria uma relação amorosa.

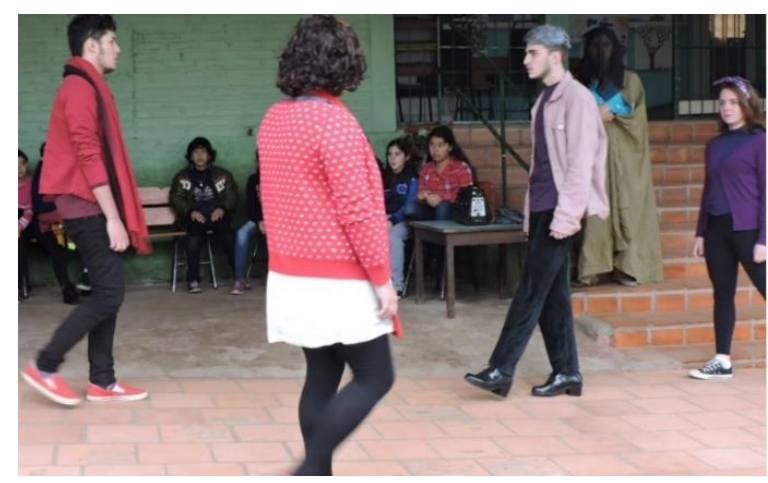

Os casais banidos

\footnotetext{
4 Todas as imagens apresentadas no texto são de autoria da bolsista PROLICEN, co-autora deste texto.

${ }^{5}$ Estudantes de Teatro: Amanda Pedrotti, Daniel Augusto, Eder Raimundi, Guilherme Lumertz, Júlia Victória Guedes e Victoria Blini Strasser.
} 
Ao assistirem à coreografia, as crianças olharam curiosas para os casais homoafetivos que estavam dançando. Depois da dança, casal por casal, foi à sala do tribunal para que as crianças - como cidadãos do reino - os julgassem por terem infringido a ordem do rei. Cada casal teria direito a um representante "contra" e um a "favor" para explicar porque eles deveriam, ou não, ficarem juntos. O próprio grupo se dividiu para ouvir os casais, criar os argumentos e expô-los no tribunal. As crianças se mostraram muito conscientes, dando mais importância ao sentimento do que a sexualidade. Esse foi um episódio que mexeu com todos os envolvidos, assim como relatou a atriz convidada Amanda Pedrotti (participante do GETIs):

Então, durante a dança eu não me mantive atenta aos olhares deles, mas, uma vez que outra, cruzava os olhos e eles estavam com uma expressão um pouco admirada, um pouco curiosa. Quando fomos ao julgamento, percebi que as pessoas que eram contra eram meninos e somente uma menina, e isso me despertou uma certa curiosidade, mas quando eles levaram os argumentos, a sexualidade, aparentemente, foi o que menos importou. Fiquei emocionada ao ouvir uma menina rebatendo o argumento do time alheio, alegando que o amor deveria prevalecer. Eu, certamente, não saberia o que falar se caso eu precisasse dizer algo. A forma que eles lidam, a pureza [...] o quanto eu queria que o mundo fosse enxergado através do olhar da criança. (2017, relato oral).

No sexto episódio, chamado de "A vidente", uma personagem convidada ${ }^{6}$ se apresentou como conhecedora do futuro, para trazer notícias e imagens de violências que aconteceriam depois do ano de 1682. Selecionamos imagens de guerras (II Guerra Mundial, Guerra na Síria, Guerra do Vietnã, Palestina e Israel) e de problemas atuais (fome, homofobia, transfobia, violência contra a mulher, bullying, gordofobia, racismo e invasão às terras indígenas). Depois, foram separadas duas imagens por grupos de crianças e essas deveriam encenar a história "contida" nas imagens a partir de suas leituras. Após o compartilhamento das cenas, fomos ao gramado onde a Vidente fez uma ciranda com as crianças com pedidos delas para o futuro e, no fim, os clãs, que ainda estavam impedidos de se comunicar, pensaram em uma ação de reconciliação para todos viverem em paz.

As crianças colocaram, nesse dia, suas vivências nas histórias das guerras e, ao realizarmos a ciranda, gritavam para que o futuro as ajudasse com assuntos bem pessoais. Esse fato pareceu dialogar com o que afirma David Novitz (1997, apud Cabral),

${ }^{6}$ A estudante de Teatro Elisa Lemos. 
de que "[...] as histórias pessoais são construídas da mesma forma que um artista cria sua arte, selecionando e ordenando experiências em um banco de memórias pessoais que se torna o significante de nossa identidade" (2006, p. 114). Percebemos que elas estavam totalmente imersas no processo, preocupadas com as ações da reconciliação.

O sétimo, e último episódio, teve o nome de "Rei Paulo, o Senhor da Boca do Monte"7, o personagem convidado representou o Pai da Princesa Jade e todos os cidadãos se apresentaram a ele. Houve, depois, as ações de reconciliação dos clãs. O clã dos Guerreiros de Sangue fez um poema e cada membro deu uma flor a alguém do outro clã, na qual estava escrito "seja a paz que você quer para o mundo". E o clã Sanserine, fez uma dança, uma carta e, depois, um grande abraço coletivo. Um decreto do rei revelou o assassino a partir das histórias criadas pelas crianças:

Após as investigações realizadas sobre os homicídios ocorridos no dia do baile de aniversário da Princesa Jade pelas duas detetives do Rei e a análise das evidências do incidente a partir dos objetos das vítimas e de depoimentos coletados junto aos cidadãos dos clãs Guerreiros de Sangue e Sanserine, o conselho real chegou à seguinte conclusão: o príncipe de um reino falido, Diego de Éscalo, soube da prosperidade do Reino de Saint Mary e disfarçou-se de coreógrafo da corte ensinando os cidadãos da cidade a dançar para a festa da Princesa, com o intuito de se aproximar dela. Ao chegar no reino reconheceu que havia outros dois pretendentes à mão da Princesa, o ferreiro Irineu e o príncipe Gabriel. Com o desejo de eliminar esses adversários, armou então uma emboscada, enviando uma carta em nome da Princesa Jade e fazendo com que seus dois rivais acabassem se matando no jardim atrás do castelo, na noite do baile. Descobrimos e prendemos o culpado, agora necessitamos que os cidadãos justos de Saint Mary decidam o destino do Príncipe Diego.

A decisão dos cidadãos para a penalizar o criminoso foi que esse deveria trabalhar para sustentar as famílias dos falecidos. Surpreendeu-nos a decisão dos estudantes pela maturidade demonstrada em aplicar uma pena que evidenciou uma noção de solidariedade. Para nos despedirmos do "Reino de Saint Mary", fizemos um grande piquenique. Foi um episódio emocionante para todos que participaram.

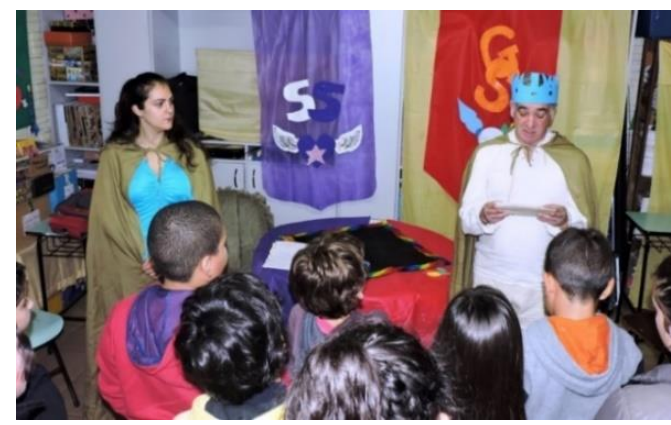

Princesa Jade, rei Paulo e os cidadãos do Reino

${ }^{7}$ Antigo nome da cidade de Santa Maria, quando ainda Freguesia no ano de 1837. 
$\mathrm{Na}$ avaliação final, realizada após uma semana do término do processo, constatamos, pelas falas das crianças, que elas conseguiram explorar a relação entre ficção e realidade, compreendo o "contexto ficcional" como uma convenção do teatro. Como aponta Cabral, "É este espaço de fronteira, entre ficção e realidade, entre possibilidades de interpretação, entre o contexto do drama e o material encontrado, que instaura um estado de jogo e o engajamento físico e emocional dos participantes" (2011, p. 116). O relato da professora regente apontou que: "A experiência mexeu, com certeza, com as emoções dos pequenos e proporcionou espaço para reflexões sobre o papel de cada um no grupo, a importância do respeito à diversidade, o preconceito, e a necessidade do trabalho em equipe" (2017, relato oral).

Ao longo do processo, o envolvimento e a imersão das crianças nas propostas, o prazer de jogar e experimentar esse universo ficcional, fez-nos perceber uma semelhança entre essa disposição e o que Souza (2014) denomina "estado de recreio". Sobre essa aproximação de estados que trataremos a seguir.

\section{O Estado de Recreio}

Ao longo do processo de Drama, anteriormente discutido, verificamos o quanto as crianças se envolveram com a proposta. Um simples pedido para ir ao banheiro se transformou em: “_sua alteza permite que eu vá aos jardins do castelo tomar um ar?”. Era evidente a mudança de postura ao iniciarem a sessão de Drama: atenção aos acontecimentos, manutenção do "corpo do personagem" criado, uso de vocabulário "rebuscado", estabelecimento de relações com os pares, preocupação em manter as convenções de tempo e espaço criadas, entre outras demonstrações desse estado de jogo que se criava dentro do processo.

Observamos que, ao imergirem no contexto ficcional, as crianças pareciam apresentar características que são evidenciadas por Souza como pertencentes ao recreio escolar. Para essa autora:

O recreio aparece hoje como um dos lugares estáveis e rotineiros de encontro entre as crianças, urbanas, moradoras de prédios ou condomínios. O espaço, tempo e estado do recreio permitem que as crianças se relacionem, se conheçam, brinquem, joguem, corram, conversem dentro da instituição escolar. A hora do recreio é um dos poucos momentos e lugares em que as crianças estão livres para fazer o que desejarem. (SOUZA, 2014, p. 19). 
Para Delalande e Simon [...] "as crianças se experimentam no pátio. Elas se experimentam numa situação ou outra para se testar, para se descobrirem elas mesmas. É mais ou menos como se pudessem provar máscaras” (apud SOUZA, 2014, p.19). Observando as palavras desses autores, parece-nos haver uma semelhança entre o estado que as crianças demonstram ao imergirem num processo de Drama com o que apresentam no recreio escolar. Essa alteração de "presença" dentro da sala de aula, faz com que reflitamos sobre o quão possível é propor um modo de ensino-aprendizagem que priorize o prazer de jogar e de aprender de forma lúdica, estabelecendo relações com os pares, dissolvendo hierarquias, assim como ocorre nas brincadeiras do pátio.

Souza aponta que:

Ao pensar o pátio da escola, como a rua da instituição, onde todos passam e nela permanecem por um tempo, tenho esse espaço como a alma da escola. É ali que as crianças se encontram, conversam, fazem acordos. Brigam, se isolam, trocam coisas, comem, brincam, correm, fogem. Desencontram-se. O amor das crianças pela hora do recreio concretiza-se no toque do sinal, quando todos saem de suas salas gritando, correndo, ávidos pelo tempo e pelo espaço fora da sala de aula. Pouco tempo, considerando que ficam na sala de aula quatro horas diárias. (SOUZA, 2014, p. 58).

No Drama, a partir das falas das crianças e dos seus modos de atuar e se expressar, percebemos que elas parecem agir como se estivessem no recreio, no pátio. $\mathrm{O}$ silêncio e a imobilidade, entendidos por alguns educadores como fundamentais para que uma aprendizagem ocorra, são convertidos em jogo, em criação teatral, em prazer, numa sessão de Drama. Souza cita Delalande (2001), o qual argumenta “[...] que o recreio é um dos poucos espaços e tempos em que as crianças encontram seus pares, sem muita vigilância dos adultos, e que compartilham seus conhecimentos, experiências, frustrações e brinquedos". (SOUZA, 2014, p. 60).

Nesse espaço de experimentação artística, ao estudante é aberta a possibilidade de se colocar como sujeito criador e de trazer para o campo estético seus desejos, suas vivências, inquietações, entre outras possibilidades, performatizando esses materiais. Cabral e Pereira (2017), inclusive aproximam o Drama da Performance ao colocarem que:

'O que acontece' no Drama e na Performance não tem a ver com incorporação ou codificação de significados específicos e fechados - os participantes articulam ideias artísticas, éticas e políticas, através da vivência estética, para dar forma a memoriais, testemunhos, manifestos políticos e protestos. Essa característica curta e afiada do texto de ambas as manifestações artísticas permite que os sentidos sejam ativados e que apontem para o que está por trás de seus textos. (CABRAL; PEREIRA, 2017, p. 297). 
Um espaço de jogo é instaurado e a aula de Teatro parece ativar estados de liberdade, criatividade e cumplicidade que em outras disciplinas do currículo nem sempre são permitidos, incentivados e potencializados. Nesse sentido, um dos desafios que se configura para uma prática educativa que se proponha a evocar um estado de ludicidade em sala de aula, seria o de rever o posicionamento do professor nesse processo. O Drama propõe ao condutor que medeie a experimentação como parceiro de jogo, afastando-se da posição de "vigilante" do comportamento dos educandos. Se o mediador estabelece uma aprendizagem de modo lúdico, por mais que a criança no começo possa apresentar resistências, ela parece se entregar na medida em que se sente contribuindo com a construção de saberes. Entregue ao jogo, assim como no recreio, ela aprende.

As performances individuais e coletivas são acentuadas em um processo de Drama, o que leva o participante a se perceber como criador da narrativa, fazendo com que o jogo artístico se dê por meio de sua presença efetiva/afetiva na proposta. Nesse espaço, subjetividades, dramaturgias e culturas diferentes interagem no campo do ensino e do espetáculo. O conceito de 'presença', portanto, é central no espaço do Drama na escola, uma vez que o enquadramento inicial convida os participantes a 'serem um outro alguém'. (CABRAL; PEREIRA, 2017, p. 297).

Esse espaço para se colocar como indivíduo ativo dentro do grupo, pareceu gerar uma maior autonomia dos participantes perante as situações que eram postas para serem exploradas ou mesmo em relação aos conflitos que surgiam entre eles que não se relacionavam diretamente à experimentação. As crianças discutiam, algumas vezes choravam, mas elas mesmas mediaram as desavenças e incentivaram os colegas a fazerem as pazes.

Conforme os encontros iam ocorrendo, o relacionamento entre as crianças melhorava e era como se não necessitassem de um mediador para sanar os conflitos. Essas atitudes "autogestoras" também se assemelham às ações do recreio, quando as crianças, sem o adulto por perto, administram os acontecimentos. Nesse sentido, a criança aprende no contexto ficcional a agir diferente no mundo real, ou seja, experimenta formas de agir por meio dessa situação dramática em eventos que ocorrem fora do espaço de jogo.

Para Delalande (2009), no recreio é possível identificar uma "micro-sociedade", na qual as crianças convivem e interagem com o outro, aprendem a desenvolver respeito ao espaço, a ter tato, a ousar se comunicar, colocar-se diante das situações, a dividir seus 
lanches, brinquedos, angústias. Para essa autora, além de momentos prazerosos e lúdicos, o recreio proporciona, também, a observação das crianças em sociedade, entre seus pares, com cenas conflituosas, de disputas, brigas e de lutas pelo poder e pelo espaço.

As interações são fundamentais para que um processo de Drama se estabeleça e proporcione aprendizagens significativas para os participantes, como aponta Pereira:

O Drama necessita que os participantes se apropriem da situação criada e, a partir das interações, criem respostas para o encaminhamento da narrativa, apropriando-se, dessa forma, das estruturas da linguagem teatral. Na relação estabelecida com o professor (parceiro mais experiente), e com os outros participantes do processo, os estudantes terão a oportunidade de ampliarem suas formas de comunicação e expressão através do uso consciente do teatro como linguagem. (PEREIRA, 2015b, p. 181).

As micro-sociedades ficcionais - no caso do processo relato, os clãs - exigem das crianças que interajam com o outro, distribuam as vozes, compreendam a função de cada papel ficcional na estrutura da comunidade criada. Essas relações que se estabeleciam na ficção podiam ser observadas também no "mundo real", quando, por exemplo, ao participarmos do recreio, era evidente a proximidade daqueles que não costumavam se reunir em sala de aula, passando a brincarem juntos nesse intervalo.

Outras mudanças também foram percebidas; as próprias crianças relataram melhoras nas outras aulas, algumas afirmaram que estavam menos tímidas e compreendendo que teatro podia ser feito de outras maneiras. Tivemos relatos da professora regente de que os estudantes começaram a se expor em outros momentos, inserindo-se em discussões, atividades artísticas e eventos da escola.

Ao relacionar o Drama com o Estado de Recreio da criança, notamos também a ansiedade e o entusiasmo emergirem. Durante as aulas é comum vermos crianças ansiosas e aflitas para a chegada do recreio, no caso do "Reino de Saint Mary", durante a semana, conforme o relato da professora regente, as crianças ficavam questionando quando seria o próximo encontro. Quando a bolsista entrava na escola para a realização do encontro, muitas vezes as crianças a recebiam no pátio, comentavam euforicamente sobre o episódio anterior, e perguntavam como seria o episódio daquele dia. No fim dos encontros, percebíamos a feição das crianças e comentários como: "Mas, já acabou?", “Princesa Jade vou sentir sua falta!", entre outras expressões que nos alegravam por perceber que, de fato, o trabalho as afetava de alguma maneira. 
A cada episódio as crianças criavam novas ações e situações; entregues ao processo, disponíveis ao jogo, dividiam seus pensamentos, emoções, sensações entre si e com as condutoras que se tornaram suas parceiras de criação de um "Reino" que pertencia somente àquele espaço, impossível de ser repetido. Um "Reino" vivido no "aqui e agora" da experimentação e que se encerrou, como quando toca o sinal para o fim do recreio, mas que, assim como o suor que permanece no corpo após as corridas no intervalo, acreditamos que permanecerá, de alguma forma, em cada um e cada uma que vivenciou o processo, como em nós permaneceu.

\section{Algumas Considerações}

Analisando o processo de Drama discutido neste artigo, é possível defender a semelhança do estado que as crianças experimentam na situação ficcional que o Drama propõe com o modo que elas agem no recreio. Evidenciou-se, ao longo de toda a experimentação, uma mudança de postura dos estudantes ao iniciarem cada episódio e a manutenção das convenções propostas, apropriando-se, pouco a pouco, do teatro como forma de comunicação e expressão de ideias, desejos, dúvidas, questionamentos e provocações que possuem no dia a dia e que reverberaram na situação ficcional criada. Uma abordagem diferenciada daquelas tradicionalmente praticadas no ensino do teatro, que desconsideram, muitas vezes, o repertório e o universo social e cultural das crianças.

Outro fato que nos convoca a pensar sobre o Drama na escola é sua potência como modo de ensino-aprendizagem do teatro que prioriza a construção coletiva de saberes, de forma lúdica, criativa e performativa, que solicita ao professor que se coloque como parceiro/mobilizador dessas aprendizagens. A criança, ao se entregar ao processo criativo, assim como no recreio, aprende, adquire gosto pelo aprendizado e se torna protagonista de suas criações.

Como reflexão final sobre o processo, vemos que, além da importância da disponibilidade para o jogo, da instalação de um estado de presença semelhante ao que assumem no recreio, para que o Drama aconteça é necessário que o mediador do processo esteja, também, disponível à construção coletiva dos saberes teatrais. Com o auxílio da professora regente, que manteve as propostas do Drama, trabalhando questões relacionadas ao processo durante a semana em outras disciplinas, conquistamos uma 
maior imersão das crianças no Reino de Saint Mary. Parece-nos que parcerias como essas que o ensino, de uma maneira geral, solicita.

Por fim, acentuamos as possibilidades de se trabalhar com temas contemporâneos dentro de um processo. Ainda que "localizados" em 1682, as crianças discutiram homofobia, xenofobia, transfobia, violências e discriminações de toda e qualquer espécies, além de temas de seu cotidiano, evidenciando aprendizagens para além da sala de aula, tão necessárias nos dias de hoje.

$$
* * *
$$

\section{REFERÊNCIAS}

BOWELL, Pamela; HEAP, Brian S. Planning Process Drama: enriching teaching and learning. Londres: Routledge Taylkor \& Francis Group, 2013.

CABRAL, Beatriz. Presença e processos de subjetivação. Revista Brasileira de Estudos da Presença, Porto Alegre, UFRGS, v.1, n.1, p. 107-120, 2011.

CABRAL, Beatriz. Drama como método de ensino. São Paulo: Editora Hucitec, 2006.

CABRAL, Beatriz; PEREIRA, Diego de Medeiros. O espaço de jogo no Contexto do Drama. Revista Urdimento, Florianópolis, v.1, n. 28, p. 285-301, julho, 2017.

DELALANDE, Julie. Aprender entre crianças: o universo social e cultural do recreio. In: LOPES, Jader Janer Moreira; MELLO, Marisol Barenco de. (org.). O jeito de que nós crianças pensamos sobre certas coisas: dialogando com lógicas infantis. Rio de Janeiro: Rovelle, 2009. p. 23-41.

O'NEILL, Cecily. Drama Worlds: a framework for process drama. Portsmouth, Heinemann, 1995. 
PEREIRA, Diego de Medeiros. Drama na Educação Infantil: experimentos teatrais com crianças de 02 a 06 anos. Florianópolis: Programa de Pós-graduação em Teatro/Universidade do Estado de Santa Catarina, 2015a. Tese (Doutorado em Teatro).

PEREIRA, Diego de Medeiros. Drama e a teoria histórico-cultural: interlocuções possíveis. Revista Urdimento, Florianópolis, v.1, n.24, p. 174-185, julho, 2015b.

PRADO, Patrícia Dias. Quer brincar comigo? Pesquisa, brincadeira e educação infantil. In: FARIA, Ana Lúcia Goulart de; DEMARTINI, Zeila de Brito Fabri; PRADO, Patrícia Dias (org). Por uma cultura da infância: metodologias de pesquisa com crianças. Campinas, SP: Autores Associados, 2009. p. 93-111

SOUZA, Karla Righetto Ramirez. As crianças e o recreio: Investigando as relações de pares nos primeiros anos do Ensino Fundamental. Rio de Janeiro: Programa de Pósgraduação em Sociologia/Universidade do Rio de Janeiro, 2014. Tese (Doutorado em Sociologia).

VIDOR, Heloise. Drama e Teatralidade: o ensino do teatro na escolar. Porto Alegre: Editora Mediação, 2010.

Recebido em agosto de 2018. Aprovado em outubro de 2018. Publicado em dezembro de 2018. 